\title{
El impacto de las telecomunicaciones en la educación virtual y en la consolidación de la democracia en Colombia ${ }^{1}$
}

\author{
DIANA PATRICIA ARIAS HENAO ${ }^{2}$ \\ UNIVERSIDAD MILITAR NUEVA GRANADA \\ FUNDACIÓN UNIVERSITARIA AGRARIA DE COLOMBIA
}

Recibido, enero 05 de 2015

Concepto evaluación, febrero 02 de 2015

Aceptado, marzo 16 de 2015
Referencia: Arias Henao, D.P. (2015). "El impacto de las telecomunicaciones en la educación virtual y en la consolidación de la democracia en Colombia". Revista Academia y Virtualidad, 8, (1), 99-110

\section{Resumen}

El objetivo de este artículo de reflexión consiste en estudiar el impacto que han tenido las telecomunicaciones en la educación colombiana, y cómo estos nuevos accesos virtuales a la formación y capacitación representan una plataforma importante para cerrar las brechas entre iletrados y letrados, lo que redunda de manera específica en la consolidación de la democracia.

La metodología es de tipo descriptiva en cuanto al pasado, presente y futuro de las telecomunicaciones en el campo de la educación virtual en Colombia, a través de un recorrido jurídico-político, mediante la utilización de fuentes primarias, que mostrarán la facilitación de la efectividad en los derechos fundamentales de información, comunicación y educación, independientemente del espacio donde se desarrolle el proceso de enseñanza-aprendizaje.

Así se pretende derrumbar barreras académicas y costumbres sociales, que coadyuven al ejercicio de los derechos políticos, mediante el incremento de población con capacidades de discernimiento, consolidado en herramientas adquiridas a través de las academias virtuales.

Palabras clave: educación virtual, Colombia, telecomunicaciones, derechos humanos, democracia.

1. Artículo de reflexión del grupo de investigación Estudios Internacionales y Políticos, Universidad Militar Nueva Granada, de la línea Derecho de las Relaciones Internacionales, Centro de Investigaciones de Relaciones Internacionales de la Facultad de Relaciones Internacionales, Estrategia y Seguridad. Adicionalmente, otras investigaciones realizadas por la autora desde el Programa de Derecho de la Fundación Universitaria Agraria de Colombia.

2. Docente Tiempo Completo e Investigadora, Facultad Relaciones Internacionales, Universidad Militar Nueva Granada y Programa de Derecho, Facultad Ciencias Jurídicas y Sociales, Fundación Universitaria Agraria de Colombia; Abogada, conciliadora extrajudicial en derecho; especialista Derecho Telecomunicaciones, Universidad del Rosario (Colombia); Magíster, Relaciones Internacionales; Doctora con grado distinguido en Relaciones Internacionales, Universidad Nacional de La Plata (Argentina).Contacto: ariashenaoabogados@hotmail.com 
El impacto de las telecomunicaciones en la educación virtual y en la consolidación de la democracia en Colombia

\title{
The impact of telecommunications upon online education and Colombian democracy consolidation
}

\begin{abstract}
This paper aims to study the impact that telecommunications have had upon Colombian education, and how these new virtual access ways to education and training symbolize a significant platform to bridge gaps between illiterate and literate people, resulting specifically in a democracy consolidation.

The methodology will be descriptive because it is detailing past, present and future of telecommunications in the virtual education in Colombia through a legal-political tour using major sources, showing effectiveness of the fundamental rights of information, communication and education, regardless the context where the teaching-learning process is being developed.

We purport to break down academic barriers and social customs, contributing to enforce political rights by increasing citizens with sound and well-structured judgment thanks to tools acquired through network academies.
\end{abstract}

Keywords: virtual education, Colombia, telecommunications, human rights, democracy.

\section{O impacto das telecomunicações na educação virtual e na consolidação da democracia na Colômbia}

\section{Resumo}

O escopo deste artigo de reflexão consiste em estudar o impacto que tem tido as telecomunicações na educação colombiana, e como estes novos acesos virtuais à formação e capacitação representam uma plataforma importante para fechar a brecha entre iletrados e letrados, o que redunda de jeito específico na consolidação da democracia.

A metodologia é de tipo descritiva em quanto ao passado, presente e futuro das telecomunicações no plano da educação virtual na Colômbia, através de um percurso jurídico-político, mediante o emprego de fontes primárias, que mostrarão a facilitação da efetividade nos direitos fundamentais da informação, comunicação e educação, independente do espaço onde se desenvolver o processo de ensino-aprendizado.

Assim, pretende-se derrubar barreiras académicas e costumes sociais que coadjuvam ao exercício dos direitos políticos, mediante o incremento da população com capacidade de discernimento, consolidado nas ferramentas adquiridas, através das academias virtuais.

Palavras-chave: educação virtual, Colômbia, telecomunicações, direito humano, democracia. 


\section{Introducción}

La globalización y el proceso neoliberal catapultó a las telecomunicaciones como el bálsamo que suavizó las fronteras rígidas soberanas, que se empezaron a flexibilizarse al unísono de los sujetos y actores internacionales, mediante el uso de las nacientes tecnologías contemporáneas.

Los sujetos internacionales cuentan con personalidad jurídica pública internacional, es decir, poseen la capacidad de interactuar a nivel jurídico-político en la sociedad internacional.

Mientras que los actores internacionales no cuentan con la facultad de celebrar tratados o acuerdos internacionales por carecer de personalidad jurídica pública internacional, pero sin embargo, influencian las decisiones que adoptan los gobiernos a nivel soberano y, a su vez, en la interacción exógena en el marco de la sociedad internacional.

Preferimos el concepto de sociedad internacional al de comunidad internacional para referirnos a la realidad del sistema internacional entrando el 2015, puesto que entre sujetos y actores subsisten latentes contradicciones en cuanto a las querencias de los mismos.

Las comunidades encuentran generalmente afinidades en los fines y conductas a desarrollar, mientras que las sociedades conllevan infinidad de contradicciones ideológicas. Es por ello que dentro de una sociedad existen diversas comunidades.

Ahora bien, el concepto de la sociedad de la información encontró sus orígenes con el advenimiento tecnológico de las telecomunicaciones y de la neoliberalización del mercado. Si bien, los orígenes no son de antaño, su influencia parece haberse triplicado. Un ejemplo de ello lo constituye un servicio de valor agregado de las telecomunicaciones: internet; red pública mundial que actúa como telaraña de redes de comunicaciones, referenciada como la gran red de redes y cuyos orígenes se remontan al marco de la Guerra Fría.
El gobierno norteamericano creó en 1969 el Proyecto de la Agencia del Pentágono (ARPA), una interconexión de computadores en red descentralizada que posibilitó el envío de la información por canales alternos en caso de que algún nodo resultase destruido en el contexto belicista. El uso originario que se enmarcó en las labores de inteligencia militar se extendió durante 1970 a otras utilidades dentro de los desarrollos de diversas comunidades científicas para que entrada la década siguiente, las universidades con actividades académicas y de investigación más destacadas, introdujeran a la red de redes, como una herramienta fundamental de trabajo.

Finalmente, desde 1990 el uso de la red se neoliberalizó y comercializó sus beneficios a los mercados públicos y privados. Tornándose en el establecimiento de comercio virtual donde ocurren gran parte de las operaciones comerciales contemporáneas. Entrando en escena:
[el] efecto bumerang del patrón económico aplicado acríticamente en Colombia y basado en el modelo neoliberal... responsable del empobrecimiento más elevado que marcó el descenso social de estratos, especialmente, de la clase media alta, y qué decir, de los estratos más bajos, hacia una lumpenización (Hernández, 2008).

Lo anterior finalmente generó más barreras de acceso a los servicios, en especial, de educación superior, para lo cual los servicios de telecomunicaciones, ofertaron nuevos espacios virtuales de formación académica.

Asimismo, los tradicionales servicios de telecomunicaciones de difusión, la radio y la televisión, igualmente como medios masivos, resultan indispensables al momento de concretar las garantías democráticas. Definitivamente, son las herramientas fundamentales en la construcción de conocimiento societal en cuanto a la efectividad de la información como derecho humano, se refiere. Igualmente, "los derechos humanos son principios generales del derecho y/o costumbre internacional vinculantes para las organizaciones internacionales en general...cuestionadas por su poca operatividad" (Burgos; 2015: 261). 
El impacto de las telecomunicaciones en la educación virtual y en la consolidación de la democracia en Colombia

Retomando a los servicios de difusión tradicionales, es menester resalta que fueron tipificados a través de las normas del Decreto 1990 de 1990 como aquellos servicios donde la comunicación se realiza de un punto hacia otros puntos simultáneamente, lo que los diferenciaba, de los servicios de valor agregado como lo es la Internet.

Al revisar, por ejemplo, la regulación de la televisión colombiana, nos encontramos con que el legislador determinó que la finalidad del medio debe enfocarse en formar, educar, informar veraz y objetivamente y recrear de manera sana, al tiempo que aplicar sus principios rectores sobre los fundamentos de la imparcialidad en las informaciones, la separación clara entre información y opinión, el respeto al pluralismo político, social y cultural, a la honra, el buen nombre y la intimidad de las personas; la protección a la infancia, la juventud y la familia; el respeto a los valores de igualdad; la preeminencia del interés público sobre el privado y la consecuente responsabilidad social de los medios de comunicación, que a todas luces influencian la toma de decisiones y el mantenimiento del poder político en una democracia. Es por ello que

[...] los discursos de los medios de comunicación proporcionan modelos de identidad a diferentes niveles: personales, colectivos, profesionales, subculturales, culturales, etc. Estos modelos que se muestran a los espectadores les ayudan a formar o a renegociar su identidad. (Arias, 2014: 86).

Por consiguiente, el mass-media es el principal constructor contemporáneo de los estereotipos culturales y de la identidad cultural (Alsina, 2010: 1).

\section{La importancia de la información democráti- ca y la objetividad de los mass-media}

Para resaltar la importancia de una información efectiva, con miras a alcanzar los estándares mínimos de un sistema político democrático, se requiere una población con capacidad de discernimiento. En cuando a los medios de comunicación, la Corte Constitucional ha referido que:

[...] debe distinguirse entre la libertad de expresión y opinión y la libertad para informar y recibir información. La primera no conoce, prima facie, restricciones, mientras que la segunda está limitada por la obligación de trasmitir informaciones veraces e imparciales... una vez superadas estas limitaciones, la restricción de cualquier derecho solo es jurídicamente aceptada cuando antecede una ponderación con otros derechos o bienes constitucionales, y ésta privilegia la información o la libertad de expresión (Corte Constitucional, 2000).

Entonces la sociedad de la información ${ }^{3}$ que nació aproximadamente en la década del setenta cambió la manera como las sociedades se desarrollan. Se pasó a un espacio de transición de la producción industrial unívoca a nuevos enfoques de producción de servicios.

Dentro de la diversidad de servicios, se produjo un cambio en la educación tanto pública como privada, tras la implementación de la modalidad de educación a distancia o de la academia en plataformas virtuales o modalidades presenciales que se apoyan ferozmente de las Tecnologías de la Información y de la Comunicación (TIC).

\section{El espectro radioeléctrico: columna vertebral de las comunicaciones contemporáneas}

El hombre como ser social, necesita esencialmente estar permanentemente comunicado, tras la propia posibilidad de transformación dentro del proceso globalizador manejado a través de redes -sistemas informáticos y electrónicos-, el hombre adquiere vital importancia dentro del sistema mundial y es el principal beneficiario de las

3. Es preciso identificar que, con base en la Declaración de principios de la Cumbre de la Sociedad de la Información, celebrado en Ginebra en 2003, se estableció que la Sociedad de la Información debe estar centrada en la persona, integradora y orientada al desarrollo, en que todos puedan crear, consultar, utilizar y compartir la información y el conocimiento, para que las personas, las comunidades y los pueblos puedan emplear plenamente sus posibilidades en la promoción de su desarrollo sostenible y en la mejora de su calidad de vida, sobre la base de propósitos y principios de la Carta de las Naciones Unidas. 
redes gratuitas de comunicación masiva. Por ejemplo, el uso de las TIC se tornó fundamental en las protestas masivas de las sociedades que soportan los arrebatos violentos gestados en el marco jurídico-político de la primavera árabe.

Dentro del marco general de las TIC, las telecomunicaciones a través del uso y explotación del espectro radioeléctrico, que representa la franja de frecuencias del espectro electromagnético, donde

[...] las ondas electromagnéticas como resultado de las propagaciones de los campos eléctricos y magnéticos atraviesan el espacio aéreo, resultan manipulables para entregar desde un emisor hasta un receptor, información inteligible en diversas formas: imágenes, sonidos, datos, videos, señales o información de cualquier naturaleza, por hilo, radio, medios visuales u otros sistemas electromagnéticos" (MinTIC-CRC-, 2014).

El espectro electromagnético conlleva dos connotaciones jurídicas: la primera de ellas, comprende al espectro electromagnético como elemento integrante o constitutivo del territorio colombiano conforme lo establece la Constitución Política de Colombia de 1991 en su artículo 101.

La segunda establece en diversas normas nacionales, al espectro electromagnético como servicio público, en conexidad con derechos fundamentales. Por ejemplo, el derecho a la información, a la comunicación y a la educación, entre los más representativos.

Dentro del mismo articulado superior colombiano, el 75 describe al espectro como un bien de dominio público imprescriptible, inembargable e inalienable, sobre el cual se garantiza la igualdad de oportunidades en el acceso a su uso.
Por su parte, el artículo 365 sostiene que los servicios públicos de telecomunicaciones son inherentes a la finalidad social del Estado y estarán sometidos al régimen jurídico que fije la ley.

Las telecomunicaciones entendidas como un servicio público implican una manifestación teórica, un deber ser sin contenido práctico alguno desde los puntos de vista jurídico, político, económico y técnico, puesto que esto conllevaría a que toda telecomunicación ${ }^{4}$ tiene la misma relevancia para la sociedad y desconoce al mismo tiempo la dialéctica inmersa en el desarrollo del sector.

La Corte Constitucional colombiana en Sentencia C-450 (1995), ratificó la calidad pública de los servicios de telecomunicaciones. Asimilándolos a un servicio público esencial, ya que son el medio que asegura el ejercicio y amparo, de otros derechos fundamentales.

El espectro electromagnético con su especial franja radioeléctrica es un recurso natural distribuido internacionalmente a través de la Unión Internacional de Telecomunicaciones (UIT) y regulado en Colombia, por el Ministerio de Tecnologías de la Información y Comunicación (MinTIC). De dicho recurso natural se desprenden los grandes avances tecnológicos contemporáneos, que influencian las prácticas humanas y sus diversos sectores, entre ellos, el educativo en todos sus niveles.

Así, antes de entrar a analizar la virtualidad de la Academia, es necesario establecer, que estos nuevos espacios virtuales de enseñanza-aprendizaje, conllevan antes que nuevas modalidades de consecución del derecho a la educación con mayor posibilidad de acceso, el efectivo goce de los derechos de la información y la comunicación así como sus garantías fundamentales conexas, produciendo una plataforma de lanzamiento hacia sociedades más democráticas.

4. Es preciso recordar cómo la legislación colombiana ha establecido las clases de servicios públicos de telecomunicaciones. El Título III del Decreto 1990 (1990), los divide en: 1. Servicios Básicos: portadores - teleservicios; 2. Servicios de Difusión; 3. Servicios Telemáticos; 4. Servicios de Valor Agregado; 5. Servicios Auxiliares de Ayuda; 6. Servicios Especiales. 


\section{Reseña esquemática del sector TIC en Colombia}

\begin{tabular}{|l|l|}
\hline Servicio TIC & Evolución \\
\hline Correos postales & $\begin{array}{l}\text { Empresas Privadas: Servi-Entrega, entre otras manejan la mayoría del servicio. } \\
\text { Monopolio Estatal reducido en 2014: 4-72 en liquidación (antes denominada Adpostal). } \\
\text { Correo Aéreo: Inició en 1919 a través de Scadta. }\end{array}$ \\
\hline Televisión & $\begin{array}{l}\text { Inició en } 1929 \text { bajo la presidencia de Miguel Abadía Méndez con la emisión comercial } \\
\text { de HJN (Stamato, 2005). }\end{array}$ \\
\hline $\begin{array}{l}\text { Llegó a Colombia en 1954 bajo el Gobierno Militar del General Gustavo Rojas Pinilla; } \\
\text { en la década de 1980 se crearon canales regionales y en 1998 se abrió el espacio a } \\
\text { la competencia de canales privados. En 2010 llega la TDT con el sistema europeo } \\
\text { DVB-T (TDT, 2014) y en 2012 se cambió el estándar a DVB-T2 para posibilitar el uso } \\
\text { del servicio en HD entre otras cualidades. }\end{array}$ \\
\hline $\begin{array}{l}\text { Antes de 1990: Monopolio Estatal con empresas municipales y Telecom a nivel } \\
\text { nacional. } \\
\text { 1994: Aparece la telefonía móvil ofertada por operadores privados y mixtos. } \\
\text { Los operadores locales se abrieron al mercado nacional e internacional. } \\
\text { 2002: más usuarios móviles que fijos. } \\
\text { 2003: Servicios de Comunicación Personal (PCS) - reducción precios. } \\
\text { 2008: Servicio 3G (Semana, 2009, 2 de mayo). } \\
\text { 2011: 4G HSPA 2012 red 4G LTE (Portafolio, 2012, abril 2). } \\
\text { 2014: Plan de datos 4g en Banda 4 (Banda americana de 1.800 - 1.900 MHz y la } \\
\text { Banda7 (Banda Europea de 2.100 MHz) (El Universal, 2012, junio 15). }\end{array}$ \\
\hline $\begin{array}{l}\text { LaUniversidad de los Andes administró el dominio.co entre 1991 y2004. Posteriormente } \\
\text { el Consejo de Estado trasladó la administración al hoy MinTIC. Desde 2009 mediante } \\
\text { concesión otorgó la administración del dominio a Internet S.A.S. }\end{array}$ \\
\hline Internet
\end{tabular}

\section{Revisión de antecedentes teóricos y empíricos}

La UIT es una organización internacional conformada voluntariamente, donde los gobiernos y los agentes privados, trabajan conjuntamente para armonizar las necesidades del uso del espectro radioeléctrico, debido a que por sus características técnicas, el espectro no es limitado por fronteras soberanas, que obligan a que su uso y explotación, correspondan al grueso de la sociedad internacional (UIT, 2014).

Igualmente los agentes estatales y no estatales coordinan la explotación de redes y servicios de telecomunicaciones y promueven el desarrollo de la tecnología de comunicaciones, basados en el principio de cooperación internacional, alentada igualmente por establecimientos políticos y de regulación de telecomunicaciones, operadores de redes, fabricantes de equipo y programas informáticos, organizaciones regionales de normalización e instituciones de financiación, de donde se infiere que las actividades, las políticas y la dirección estratégica de la UIT están determinadas y concebidas por el sector al que sirve (UIT, 2014).

La UIT perfila los consensos mundiales respecto del sector TIC promoviendo la conectividad global e incrementando sus beneficios transversales y dentro de todos los sectores, también pretende impulsar la enseñanza y la capacitación tecnológica relativa a las TIC.

Se estructura especialmente en 3 sectores: 7 UIT-R Radiocomunicaciones; 14 UIT-T Normalización; 2 UIT - D Desarrollo. Los pronunciamientos de los sectores no conllevan carácter vinculante al ser adoptadas mediante la figura jurídica de la recomendación (UIT, 2014). 
Las telecomunicaciones en Colombia inicialmente fueron definidas como un servicio de carácter público prestado por el Estado de manera directa o a través de concesiones que podrá otorgar en forma exclusiva a persona natural o persona jurídica, reservándose en todo caso, la facultad de control y vigilancia (Artículo 5, Ley 72 de 1989).

No obstante, desde 1954, se le refirió al campo de las telecomunicaciones el deber actuar como instrumento para el desarrollo político, económico y social del país y para la promoción y progreso de las personas, entidades y organizaciones (Decreto 3428 de 1954).

Es desde allí, que podemos remontar en el territorio nacional, el influjo de las TIC como plataforma jurídicapolítica, ligada a los mecanismos para disminuir las brechas sociales, en este caso, potencializando un nuevo espacio de acceso a la educación, con menos gastos en recursos y tiempos de desplazamiento.

Abriendolas posibilidades para que la sociedad colombiana se acerque a la consolidación de sus fines democráticos, aumentando el número de seres dotados de capacidades y competencias, para discernir democráticamente con fundamentos sólidos y no meramente mediáticos $\mathrm{y}$ mediados por reducidas élites de poder políticas y económicas.

Así, se lograría paulatinamente, "quebrar la tradicional dependencia, si se hace bien, haría redundante el papel de los dirigentes vitalicios, hombres-pivotes y vanguardias cancerberas que han monopolizado el conocimiento y los recursos y explotado indebidamente a las masas" (Fals, 1986: 54).

Posteriormente en 1993, Colombia expidió el vigente Estatuto de Contratación Estatal (Ley 80 de 1993), en el cual se conceptualizó la actividad y el servicio de telecomunicaciones, como figuras jurídicas autónomas. Actividad que refiere un servicio privado mediante el establecimiento de una red para uso particular y exclusivo, a fin de satisfacer necesidades privadas de telecomunicaciones sin conexión a las redes conmutadas del Estado o a otras redes privadas de telecomunicaciones.
Por su parte, servicio es aquel prestado tanto por personas jurídicas públicas como privadas, con o sin ánimo de lucro, mediante el cual se satisfacen necesidades específicas de telecomunicaciones a terceros, dentro del territorio nacional o a través de territorios interconectados internacionalmente.

Antes de 1990 el sector de las Telecomunicaciones en Colombia fue desarrollado mediante estructuras monopólicas estatales, conforme lo ratificamos al referir la normatividad previa a la Constitución Política colombiana de 1991 y a la consolidación de un sistema internacional neoliberal, que inyectó al sector TIC una moda de eliminación de la regulación en favor de una libre competencia sectorial, donde pautara y participara el interés privado.

Colombia en 2009 sancionó la ley TIC, que concordó con el marco constitucional que propugna el derecho a la privacidad, la libertad de expresión, el derecho a informary recibir información veraz e imparcial a todas las personas y a la administración del espectro electromagnético, entre los principales aspectos tendientes a garantizar el derecho a la comunicación, que es de doble vía. De doble vía porque atiende a la efectividad de ser comunicado y a comunicarse.

Cambio legislativo que incrementó la existencia y credibilidad de las aulas virtuales como escenarios viables, económicos y precisos, para que ciudadanos, indistintamente de sus capacidades económicas, se lanzaran a la ciberformación.

\section{Derecho a la información y a la comunicación}

Los derechos a la información y a la comunicación constituyen la base jurídico-política fundamental para la comprensión de las TIC como un derecho humano. Representan elementos esenciales para la consolidación de la democracia, cuando se comprende que el derecho a la información representa la 
El impacto de las telecomunicaciones en la educación virtual y en la consolidación de la democracia en Colombia

[...] base sustantiva del Derecho a la Comunicación $\mathrm{y}$ uno de los pilares fundamentales del Derecho Internacional de los Derechos Humanos... signo constitutivo y emblemático del sistema democrático... por tal motivo, no puede desentenderse de la necesidad de garantizar la producción de sentido democrático en el discurso mediático, contribuyendo a poner límites a los abusos y la manipulación del poder políticoeconómico que tienen por fin lograr la docilidad y la inmovilidad ciudadana (Dualdhe, 1999).

El fortalecimiento de una democracia constitucional guarda una estrecha relación con

[...] el control efectivo de los ciudadanos sobre las acciones públicas (que) requiere no sólo una abstención por parte del Estado de censurar la información sino que demanda una acción positiva consistente en proporcionarle a los individuos los medios para que accedan a los archivos y documentos en los cuales se plasma, día a día, la actividad estatal (Corte Constitucional, Sentencia, 2003).

La Corte Constitucional ha emitido jurisprudencia unificadora respecto del sentido dual que encierra el derecho a la información, de la siguiente manera:

[...] la libertad de información comporta un doble sentido: tiene que ver, por un lado, con el derecho subjetivo de la persona para difundir una información sin verse sometido a una coacción externa desproporcionada y, por el otro, con el derecho en cabeza del receptor, para recibir información veraz, oportuna e imparcial. Se reafirma así la responsabilidad social asignada a quien hace uso de este derecho... Esta debe ser, siguiendo el mandato que reconoce el derecho, veraz e imparcial (Corte Constitucional, 2000).
En consecuencia, la información termina siendo promotora de la generación de "conocimiento en las personas, pero también... de producir la comunicación entre ellas. Igualmente no se puede negar que para generar opinión pública en una sociedad (se requiere) una necesaria información suficiente" (González, 2008).

El alcance de la calidad de la información es transcendental y debe reflejarse en que "el contenido de una información obedezca a un verdadero y legítimo interés general de conformidad con la trascendencia y el impacto social" (Corte Constitucional, 2000). En cuando a las excepciones al acceso a la información solamente se admiten: "si tienen por objetivo proteger un derecho fundamental o algún bien de especial importancia, como lo es la seguridad nacional. El principio de proporcionalidad comprende tres subprincipios: 'idoneidad, necesidad y proporcionalidad en sentido estricto"” (Corte Constitucional, 2003).

Se presenta una tensión que prevé conflicto entre el derecho al buen nombre y el derecho a la información. No obstante, mientras que la información sea verdadera "y completa, no se puede afirmar que el suministrarla a quienes tienen un interés legítimo en conocerla, vulnera el buen nombre" (Corte Constitucional, 1995).

En tal sentido, "cuando la información fomentada por los medios de difusión es manipulada, desatiende su función democrática al generar una opinión pública no argumentada, castrándole su autonomía" (Jabuarybe, $2005)^{5}$.

Para ello, el uso adecuado de las tecnologías de la información, logrará que el derecho complejo de la comunicación pueda por doble vía ser efectuado. Que se comunique y sea comunicado el individuo, como elemento de la sociedad internacional, esto es, mediante canales y flujos de información confiables provenientes de tantos emisores como receptores deseen comunicarse en la distancia.

5. Los países sudamericanos se caracterizan por una condición periférica recurrente, la cual se convertirá en irreversible si no se hace algo. 


\section{Academia virtual en América Latina}

Para comprender la realidad de la virtualidad educativa en Colombia entrando el 2015, resulta pertinente contextualizarla a través del cotejo con la situación que al respecto presenta América Latina. La calidad de la información y la comunicación en la región presenta similitudes en cuanto a "injusticias, desigualdades y exclusiones y que tienden a ser propositivas en contextos históricos específicos" (Archila, 2001: 18), atribuidas a campos sociopolíticos y jurídicos.

En las últimas décadas, se ha comenzado a desarrollar a escala global y en la región latinoamericana igualmente, un nuevo "modelo económico asociado a la irrupción y generalización de nuevas tecnologías de producción" (Toffler, 1980, 2006). Resultando un novedoso paradigma derivado de la incorporación de las TIC en la educación virtual, "como modalidad formativa, que se vino generalizando con mucha rapidez en América Latina" (Corica, 2012).

La Comisión Económica para América Latina y el Caribe (CEPAL) sostuvo desde el año 2006 que en la Región, está emergiendo una economía en la que proliferan productos digitales y redes digitales concentradas en torno a internet en el marco de un nuevo escenario, donde los modos de regulación económica y de protección de los derechos intelectuales reclaman su actualización a los ambientes digitales y virtuales.

Una simple adecuación a la figura de la ficción jurídica tan utilizada por las escuelas normativas internacionales, desde inicios tan simples, como el reconocimiento de personas jurídicas o de las mismas transacciones electrónicas.

Brasil como país emergente y país pivote sudamericano, lidera los grandes avances de la región y generalmente actúa en bloque en organismos universales. Es el país que igualmente lleva la batuta en implementación y uso de las aulas virtuales en todos los niveles. De contramano, conlleva los mayores desafíos a los detractores de estos nuevos espacios virtuales.
Así ha criticado la mayoría del sector doctrinal, a los nuevos paradigmas virtuales educativos, como "o aparecimento de um novo paradigma provoca rejeições, desconfianças, incômodos, desinstala rotinas de sistemas consolidados porque questiona 'verdades' e desmonta conceitos, ameaçando estruturas administrativas conservadoras e impondo mudanças que são muitas vezes vistas com reserva e temor" (ENAP, 2006). Sin embargo, como en otros países, "las resistencias políticas o normativas son cada vez menores" (Mena, 2008).

En la región, la educación virtual en sus diferentes niveles y modalidades, representó en 2012 aproximadamente el ocho por ciento de la elección de los estudiantes. Dentro de esta estadística debemos anotar que durante la década de los 70 y 80 , la educación virtual de carácter privado dominó a la región latinoamericana, representando mayorías en México, Brasil, Ecuador, Perú, República Dominicana y Argentina. No obstante, la minoría de la región potencializó durante tal periodo a una educación virtual de carácter público, en Estados como Costa Rica, Venezuela, Honduras, Colombia y Uruguay, confiando en sus instituciones y sus regulaciones estatales para dar el salto hacia el ciberespacio.

Asimismo, como lo mencionamos al iniciar el presente artículo, la educación presencial fue inyectada de TIC, como herramientas para profundizar, agilizar, dinamizar y extender los espacios presenciales de enseñanzaaprendizaje. Al punto que son usuales las conferencias y seminarios virtuales en programas presenciales como el uso continuo de Aulas Virtuales, una especie de Facebook Académico, donde los miembros de las comunidades académicas, cierran brechas generacionales y espaciales, para fomentar una educación más interactiva y humana, así sea mediada a través de plataformas virtuales.

El profesor empieza a aparecer como una verdadera guía pero con una facha de usuario similar y no el docente que se relaciona de manera jerárquica y dictatorial en la mayoría de los escenarios presenciales de la Academia.

El uso de la virtualidad en últimas, se insertó en los espacios presenciales como en los ciberespacios. Un 
El impacto de las telecomunicaciones en la educación virtual y en la consolidación de la democracia en Colombia

ejemplo de ello, lo representa la plataforma Moodle, la cual en el escenario latinoamericano, representó el motor para flexibilizar los costos y tiempos para la capacitación y formación en distintos niveles y modalidades.

Actualmente el proceso de virtualización se ha extendido a nivel público y privado a lo largo y ancho de la región latinoamericana, generando una importante escolarización tanto de sectores que por sus condiciones socioeconómicas y geográficas no podían acceder a la educación presencial y a sectores que pudiendo acceder, optan por llevar a cabo sus formación a través de espacios virtuales por las ventajas de la flexibilización de procesos de enseñanza-aprendizaje de calidad.

Considerando que la calidad de los procesos educativos, sean en plataformas virtuales o en espacios presenciales o semipresenciales, en gran medida dependen de la intención seria de formación del estudiantado y de las capacidades del centro de educación elegido. Propiciando una mayor presencia de modalidades virtuales (IESALC, 2006).

\section{Conclusión}

Definitivamente el impacto de los desarrollos de las telecomunicaciones en Colombia a los espacios relativos a la educación básica, media y superior, aún no es posible de ser medido. Sin embargo, es posible identificar la tendencia al alza en cuanto al uso de las TIC, tanto en los espacios de educación presencial, semipresencial y virtual. Y dicha tendencia nacional debe hacerse extensiva al escenario regional y global, de manera simultánea, provocando los escenarios de internacionalización de los procesos de enseñanza-aprendizaje y la posible inclusión a futuros medianos, de esquemas educativos trasnacionales. De tal manera que los nuevos espacios de la academia virtual potencian e incrementan las comunidades en formación y capacitación que pacifican a las sociedades y las convierten en más productivas.

Una verdadera herramienta para acortar brechas entre iletrados y letrados, lo que redunda de manera específica en la consolidación de la democracia. Pues triplica la población con una real capacidad de entendimiento y de discernimiento político, y con nuevas demandas sociales inclusivas y transformadoras de situaciones críticas.

Las plataformas educativas virtuales conllevan la facilitación en la consecución del goce efectivo de los derechos fundamentales a la información, la comunicación y a la educación, de manera primigenia.

Los escenarios virtuales reproducen el derrumbamiento de barreras académicas y costumbres sociales, coadyuvando al ejercicio de los derechos políticos, mediante el incremento de población con capacidades de decisiones políticas contextualizadas y surgidas de pensamientos sistémicos no manipulables por los medios de comunicación o por las élites de poder político y socioeconómicas.

La desmaterialización del papel en materia educativa representa oportunidades para que la variable política no sea siempre superior a la variable jurídica, y se obligue a la democratización en el acceso a la educación, para poder establecer mecanismos alternativos para la alfabetización y capacitación de la población colombiana, evitando que los intereses ocultos y funcionales de los medios de comunicación hacia las bondades políticas, influencien la construcción del conocimiento de los colombianos.

En síntesis, el fenómeno de la globalización y neoliberalización que sufrieron las telecomunicaciones posteriora 1990, generó beneficios de intereses particulares y colectivos dentro de un mercado competitivo.

Requiriéndose una necesaria concertación nacional para el desarrollo de difusión masiva (mediante la participación real de medios de comunicación, del sector educativo, del Estado, de las organizaciones de la sociedad civil, del comercio y en general del ámbito particular) de una política de producción, mercadeo y consumo de bienes y servicios generados en verdadera democracia.

El impacto que general el objeto del presente artículo puede sintetizarse en las cifras más actuales otorgadas por el Ministerio de Tecnologías da la Información y las 
Comunicaciones de Colombia (MinTIC) en el primer trimestre del año 2014, así:

a. 8'883.004: Número de suscriptores de Banda Ancha.

b. 631.155: Número de suscriptores de internet con otras velocidades.

c. 9'514.159: Número de suscriptores con conexiones a Internet fijo y móvil a nivel nacional (MinTIC, 2014a).

Otro de los valores agregados de las TIC a la democracia colombiana lo representa conectividad rural. El MinTIC realizó la mayor inversión histórica para virtualizar el campo colombiano. Se destinó la cifra de 1 billón de pesos para 7.621 Kioscos Vive Digital en centros rurales de más de cien mil habitantes y la mayor entrega de computadores y tabletas a escuelas públicas: cerca de 2 millones de terminales, desde el 2010 (MinTIC, 2014b). Y se previó que para finalizado el 2014, se instalarían 630 nuevos puntos Vive Digital.

Igualmente el gobierno colombiano planea a través de SATCOL, el primer satélite geoestacionario, incrementar el número de interconexiones de internet y telefonía en más de 50.000 mil puntos en el territorio nacional. Y adicionalmente diseño el Plan Ecosistema Digital que se centra en infraestructura, servicios, aplicaciones y usuarios (Univisión, 2009, agosto 9).

En definitiva fue grande el salto legislativo que vivió Colombia en 2009, pasando de una regulación proveniente de 1990 y que se quedaba notablemente desactualizada para los avances tecnológicos que caracterizan el sector TIC a una regulación donde prima el término de convergencia de servicios, donde los valores agregados, no desbordan los límites normativos.

\section{Referencias}

Alsina, M. (2010). Los Estudios de Comunicación Intercultural Red de La Iniciativa de Comunicación. Revista de Estudios de Comunicación ZER, Universidad del País Vasco. Recuperado de: www.comminit.com. Consultado el 4.2.2013.
Arias Henao, D. (2014). Investigación Comparativa Trasncontextual en las Relaciones Internacionales Narcoviolentas.En: Revista de Relaciones Internacionales, Estrategia y Seguridad. Bogotá: Universidad Militar Nueva Granada. Vol. 9, No. 2.

Archila, M. (2001) . "Vida, pasión y ... de los movimientos sociales en Colombia". En: Archila, M, y Pardo, M, (Ed.), Movimientos sociales, Estado y democracia en Colombia, Bogotá: Universidad Nacional de Colombia, Centro de Estudios Sociales, Instituto Colombiano de Antropología e Historia, pp. 16-47.

Borda, O. (1986). Conocimiento y poder popular. Bogotá: Siglo XXI.

Burgos, J. (2015). El Banco Mundial y los Derechos Humanos: un Repaso Crítico a los Argumentos JurídicoDoctrinales. En: Revista de Relaciones Internacionales, Estrategia y Seguridad. Bogotá: Universidad Militar Nueva Granada.

Constitución Política de Colombia (1991). Bogotá: Imprenta Nacional.

Córica, J. (2014). "Educación virtual y brecha digital de segundo nivel: La responsabilidad docente frente a la división de clases intelectuales". En: Revista mexicana de bachillerato a distancia, 12, agosto. Recuperado de http://bdistancia.ecoesad.org.mx/?articulo=virtualidady-brecha-digital-de-segundo-nivel-la-responsabilidaddocente-frente-la-division-de-clases-intelectuales Consultado el 28/11/2014.

Corte Constitucional Colombia. Bogotá: Imprenta Nacional:

(1995a). Sentencia C-450/95, Magistrado Ponente, Eduardo Barrera Carbonell (1995b), Sentencia SU089/95, Magistrado Ponente, Jorge Arango Mejía.

(2000). Sentencia SU-1723/00. Magistrado Ponente, Alejandro Martínez Caballero

(2003). Sentencia C-872/03, Magistrada Ponente Clara Inés Vargas Hernández.

Declaración de principios de la cumbre de la sociedad de la información. Ginebra, Suiza 2003. 
Duhalde, E. (1999), Introducción al derecho a la información, Buenos Aires: El Bloque Editorial.

González, G. (2008). El derecho de la información del siglo XXI. www.elespectador.com; 28 julio. Recuperado el 23 de noviembre de 2009.

Hernández, A. (2008). “Cómo sería el futuro de los movimientos sociales en Colombia?" En: Antroposmoderno, Recuperado de http:// antroposmoderno.com/antro-articulo.php?id articulo=1153 el 08/12/14.

Instituto Internacional para la Educación Superior en América Latina y el Caribe (IESALC). (2006). Informe de la Educación Superior en América Latina (2000-2005). La metamorfosis de la educación superior en América Latina. Caracas: IESALC.

Jaguaribe, H. (1999). La construcción de la Unión Sudamericana, recuperado de http://www.forosur.com.ar/ pag_puntos01b.htm Consultado el 19/11/2014

Mena, M. et ál. (2008). El marco normativo de la educación a distancia en América Latina. Bogotá: UNAD Virtual Educa, ICDE, 2008.

Miklos, T. (2005). "Planeación prospectiva: una estrategia para el diseño del futuro". México: Limusa.

Ministerio de Tecnologías de la Información y las Comunicaciones, MinTIC, (2014a), Boletín trimestral de las TIC. Cifras primer trimestre de 2014, recuperado de http://colombiatic.mintic.gov.co/602/w3-article-6276. html Consultado el 18/11/2014

(2014b),Informe al Congreso, recuperado de http:// www.mintic.gov.co/portal/604/w3-propertyvalue-546. html Consultado el 30/12/2014

Portafolio (2012, abril 2). Fusión de Telefónica Telecom y Movistar, formal en abril 24, Recuperado en 19/11/2014 de http://www.portafolio.co/negocios/fusion-telefonicatelecom-y-movistar

República de Colombia. Ley 72 de 1989. Bogotá: Imprenta Nacional.

Ley 80 (1993). Estatuto de contratación estatal. Bogotá: Imprenta Nacional.
Imprenta Nacional.

. Decreto 1990 de 1990. Bogotá:

Imprenta Nacional.

Revista Semana, (2009, 2 de mayo), Un año de 3G en Colombia, recuperado de http://www.semana.com/ vida-moderna/articulo/un-ano-3g-colombia/102641-3 Recuperado el 19/11/2014

Stamato, V.(2005). “Días de radio".En: Revista credencial historia. Recuperado de http://www.banrepcultural. org/blaavirtual/revistas/credencial/junio2005/radio.htm Recuperado el 19/11/2014

Toffler, A. (2006). La revolución de la riqueza, Bogotá, Debate. El Contexto de la Reforma de la Virtualización en América Latina. Director del Observatorio de la Educación Virtual (OEA-VIRTUAL EDUCA). La Educación Superior a Distancia y Virtual en Colombia: Nuevas Realidades. (2013). Editores Arboleda, Néstor; Rama, Claudio. Colombia.

(1980). Powershift, el poder de la información, Barcelona, Plaza y Janes Rama, Claudio. (2013). El Contexto de la Reforma de la Virtualización en América Latina. Director del Observatorio de la Educación Virtual (OEA - VIRTUAL EDUCA). La Educación Superior a Distancia y Virtual en Colombia: Nuevas Realidades. (2013). Editores, Arboleda, Néstor; Rama, Claudio. Colombia.

Universal, El (2012, junio 15), Fusión Telmex-Comcel da paso a Claro. Recuperado de http://www.eluniversal.com. co/comcel/fusion-telmex-comcel-da-paso-claro-80372 Recuperado el 19/11/2014

Televisión Digital para Todos (TDT) (2014). ¿Qué es TDT? Recuperado de http://tdt.rtvc.gov.co/quees-la-television-digital-para-todos Consultado el 19/11/2014Unión Internacional de Telecomunicaciones, UIT, (2014), Comprometida con cambiar al mundo, recuperado de http://www.itu.int/es/about/Pages/vision. aspx Consultado el 19/11/2014

Univisión (2009, agosto 9). El primer satélite colombiano de telecomunicaciones toma forma, recuperado de http:// foro.univision.com/t5/Colombia/Va-tomando-forma/tdp/360025219 Recuperado el 30/12/2014 